\title{
An Adaptive Normative Multi-Agent System Using Web 3.0 for E-Learning Platform
}

Namrata Dhanda, Goel Institute of Technology and Management, Lucknow, India, ndhanda510@gmail.com

Dr. Manuj Darbari, Babu Banarsi Das National Institute of Technology and Management, Lucknow, India, manujuma@gmail.com

Dr. Neelu Jyoti Ahuja, University of Petroleum and Energy Studies, Dehradun, India, neelu@ddn.upes.ac.in

Dr. Imran Ali Siddiqui, Celerity Networks Pvt Ltd, Noida, India, imranas@gmail.com

ABSTRACT The growing concern for education and innovative technologies has led to a new dimension of learning. The paper proposes a new framework NormATel using the concept of Normative Multi-Agent system, Activity Theory and e-Learning. The basic idea of the paper is to make elearning more user specific using the concept of Web 3.0, like its ability to work on two separate modes: single user learning and community based learning. The proposed framework is verified using Deontic Logic.

Keywords : e-Learning, Norms, Activity Theory, Semantic Web 


\section{Introduction}

Developing country like India is witnessing a huge surge in demand for higher education. The volume of students applying for higher degrees in universities is increasing each year, but universities lack to cater the demand of such spur. Secondly, those students who wish to join in a particular course are unable to do so because of the limited choice available to them. E-learning provides an excellent framework to bridge the above two shortfalls. There are number of definitions given for e-learning. Keegan (1996) categorizes distance education into three basic categories: Autonomy Theory, industrialization theory and finally theories of interaction and communication. Bricken (1990) and Shneiderman (1993) also highlighted the ability to support collaboration among students as well as between students and professors.

The advancement of Web 3.0 in e-learning provides a new dimension of research in the field of collaborative learning environment. Web 3.0 engine provides excellent tagging information to the metadata being generated. Hayes (2006) describes Web 3.0 as an amalgamation of 3-D virtual environment where students can connect, communicate and interact in real time. It is a powerful tool for making application using open source software.

\section{Overview of Normative Multi-Agent System in Activity Theory}

The concepts of norms are used to define the behavior of agents in multi-agent system. Norms are defined as the set of rules and guidelines. There are three basic categories of Norms: Norms Creation, Norms Evolution and Norm Removal. The idea of mixing it with Multi-Agent is explicit support with respect to the environment. Normative system also includes meta-rules hence can be embedded with Activity Theory. Various phases of Norms include Creation, Identification, spreading, Enforcement and Emergent are applied to Activity Theory notions like: Subject, Object and Community and Outcome since Activity Theory is basically categorized as Social Learning. Engestrom suggested gradual learning phases of individual and collective learning of community.

The concept of Activity Theory was started by Vygotsky (1920). He found a correlation between psychological activities and social activities. Later on it was modified by Engestrom (2001), he described activity theory into triangular form with six basic components of universe of discourse as : Tools and Signs, Subject, Object, Rules, Community and Division of labor to generate outcome (Fig. 1). 


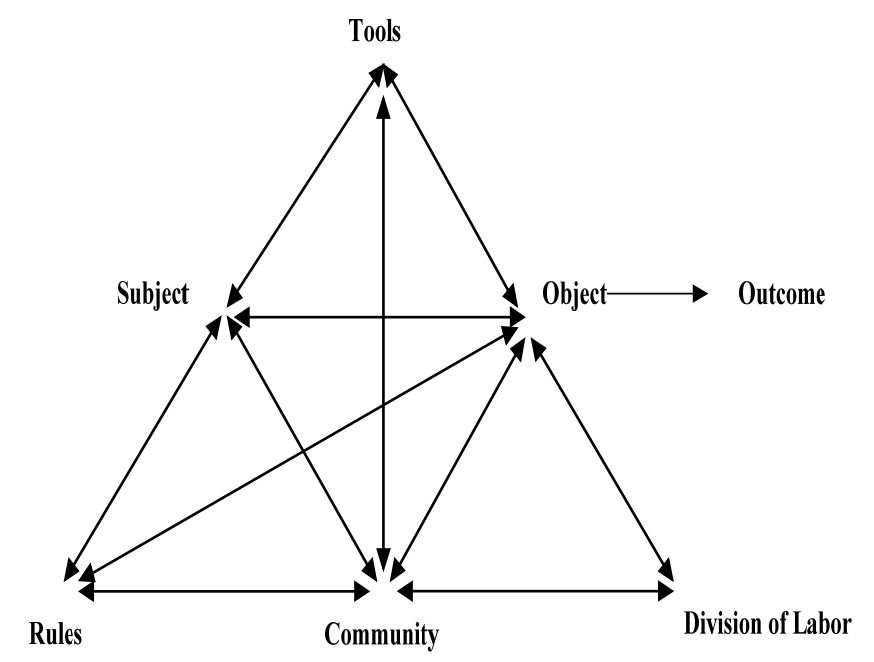

Figure 1: Engestrom's Structure of Human Activity

Fig.1 above represents a relationship between subject and object being mediated by the help of tools. The relationship between Object and Community is being mediated by the division of labor.

Later on Mwanza (2005) developed an eight step model based on the above guidelines (Fig. 2) highlighting how the activity theory system given by Engestrom can be incorporated into the system. The components of Activity Theory models are linked with Normative Multi- Agent System (NorMAS). Later on the model will be applied to formalize using Deontic Logic. The conversion of NORMS into Activity Theory starts by analyzing a competitive component framework of both the systems.

\begin{tabular}{lll} 
Activity Type & $\begin{array}{c}\text { Linguistic } \\
\text { Connectivity Norms }\end{array}$ \\
\hline A & Activity of Interest & (performed by) \\
\hline B & Objective of Activity & (has an) \\
\hline C Subject of this Activity & (supported by) \\
\hline D & Rules and Regulations & (has) \\
\hline (E) Division of Labour & (supported by) \\
\hline F Community & \\
\hline & & \\
(G) Outcome & (performed by) \\
\hline
\end{tabular}

Figure 2: Mwanza's Layerical Classification of Activity Theory 
Fig. 3 represents the conversion framework for NORMS to Activity Theory (AT) finally linked with e- Learning. Various phases of Norms as stated by B.T.R. Savarimuthu and Cranfield, (2011) gives a further categorization mechanism used in simulation based works on Norms. Creation of Norm can be correlated in Activity Theory as initiation of the process (object on which a particular process is to be executed). In e-Learning it will be defined as Student/Tutor (Identification of right tutor for right student).

Secondly, norms identification deals with implementation of norms based on the environment. In NorMAS, the agent identifies the norms based on the current situation and adjusts themselves accordingly. In Activity Theory, it is defined by the component "Subject", which finally means in e- learning as "Structured Course content based on the type of object (Student)".

Thirdly, Norm spreading deals with the distribution of features in the surroundings. It can be done by using leadership or other evolutionary mechanisms. In terms of activity theory, it is defined as Tools and Division of Labor (Technique) by which we can propagate the object.

Lastly, Enforcement represents the process of enforcement of rules by help and some form of the punishment to the violator. In terms of activity theory, it represents the rules being applied to the community. In e-learning it is defined as the setting of the standards of learning depending on the student type.

The above correlations between three classifications are applied in Web 3.0 rule for elearning using Deontic Logic Verification.

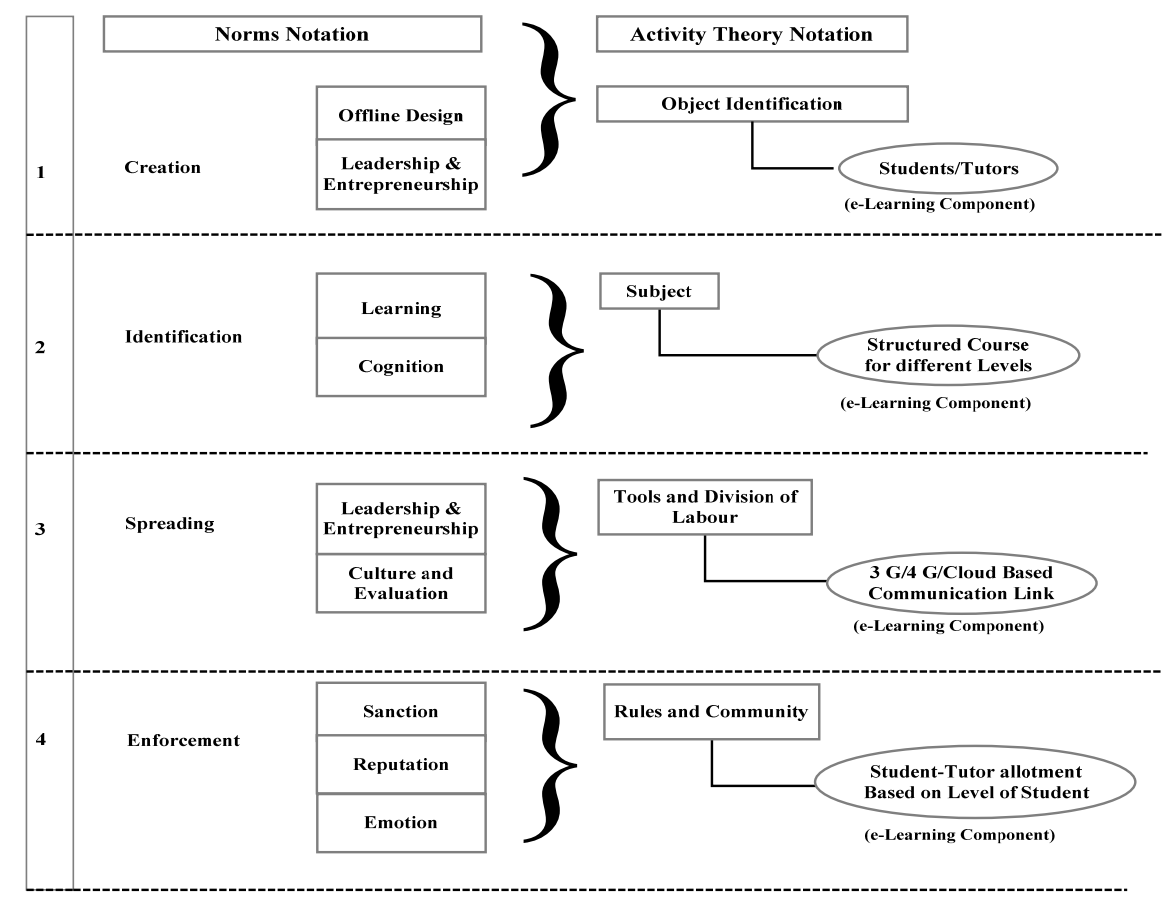

Figure 3: A relationship between NORM-AT- e Learning. 


\section{Web 3.0 e-Learning Framework}

Semantic web supports an environment which can vary from personalized to generalized, from slow pace to fast pace and finally a $4 \mathrm{G}$ support using Smart Television Set. We start with basic OWL for e-learning framework using Web 3.0.

Fig. 4 represents the co-ordination set between student registering to a particular course to the final allotment and delivery of the course. The Ontology Framework for eLearning Norms is depicted in Fig. 5.

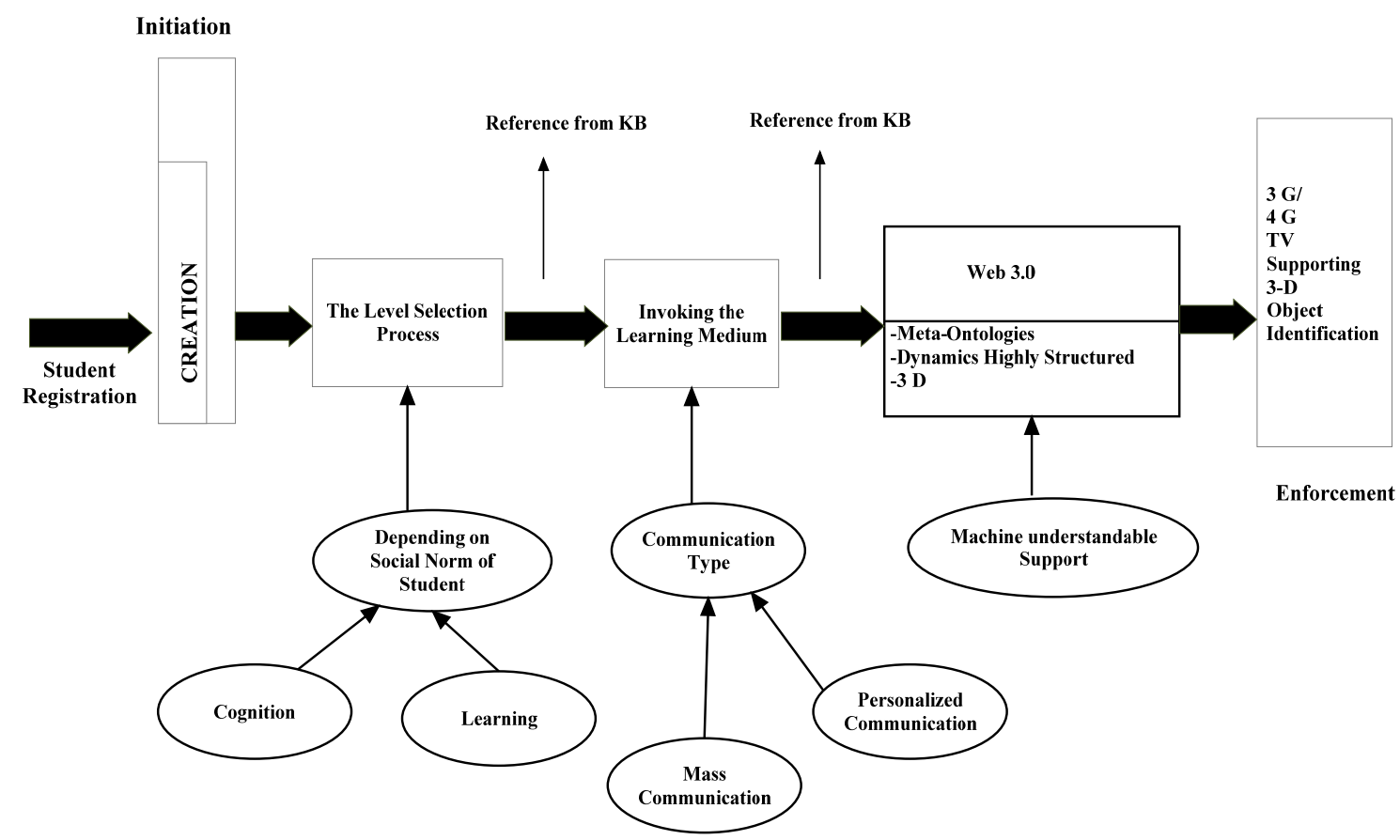

Figure 4: NORM-AT Intelligent Web 3.0 Supportive e-Learning Framework

A user will be registering for a particular course and the prerequisite will be intelligently tested by the machine depending on the type of course. 


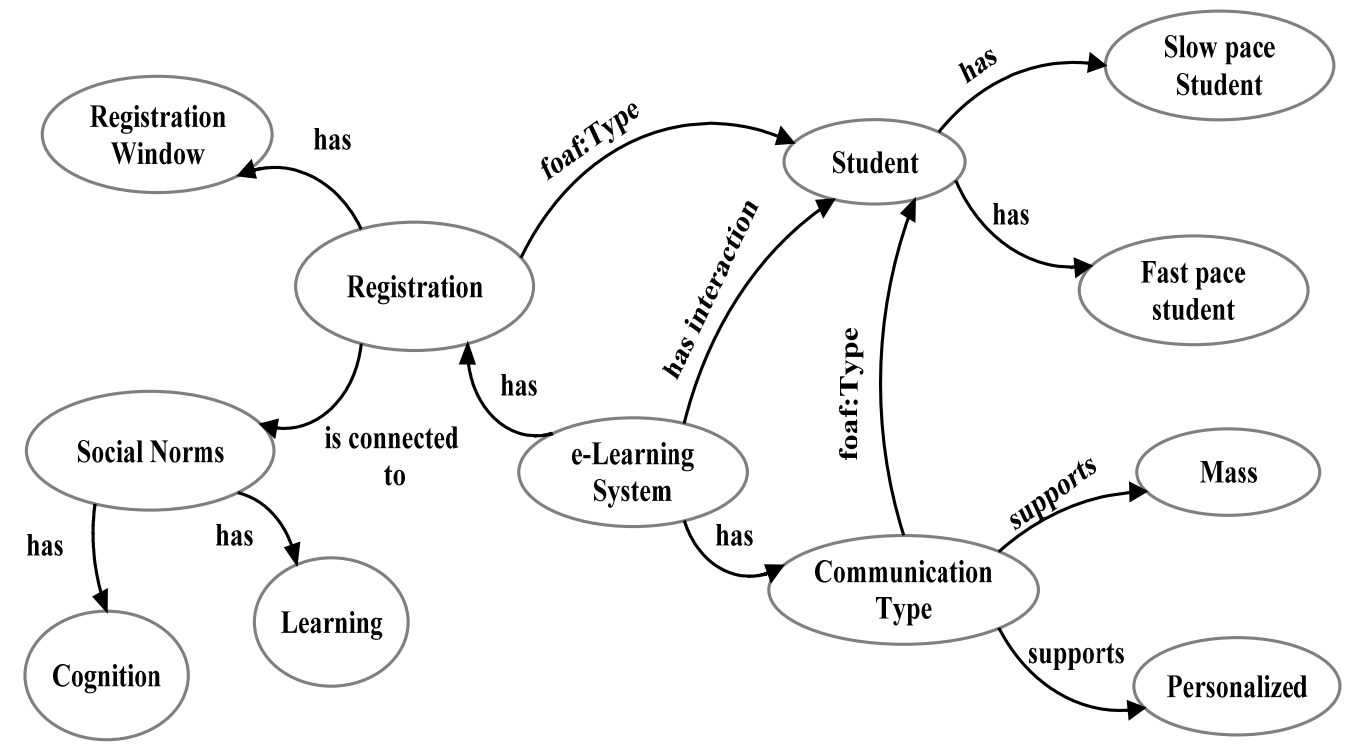

Figure 5: Ontology framework of e-Learning Norms

Selected, user will be allotted the course; this is interlinked with single user mode only. For the group learning mode, the pace of learning is decided by the tutor and there will be no check for the level of learning and its pace.

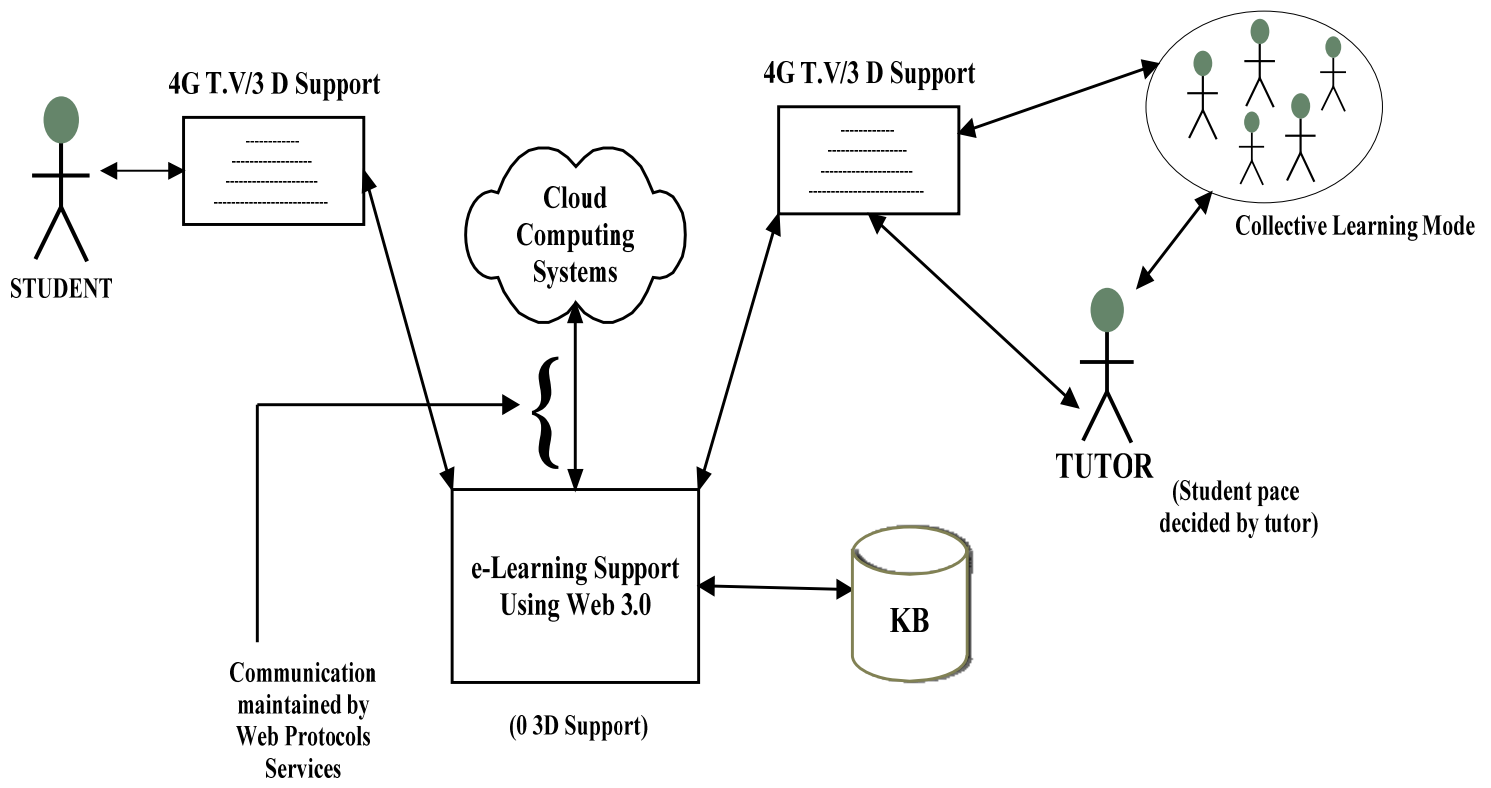

Figure 6: Web 3.0 support to e-Learning using 4 G T.V with 3-D

To apply the constraint and check the sufficiency of the model, we apply Deontic Logic. Deontic Logic is a branch of symbolic logic that deals with the following notions like 
permissible, impermissible, obligatory, omissible and optional and ought. Normally Deontic is divided into three fold partition of propositions (Fig. 7).

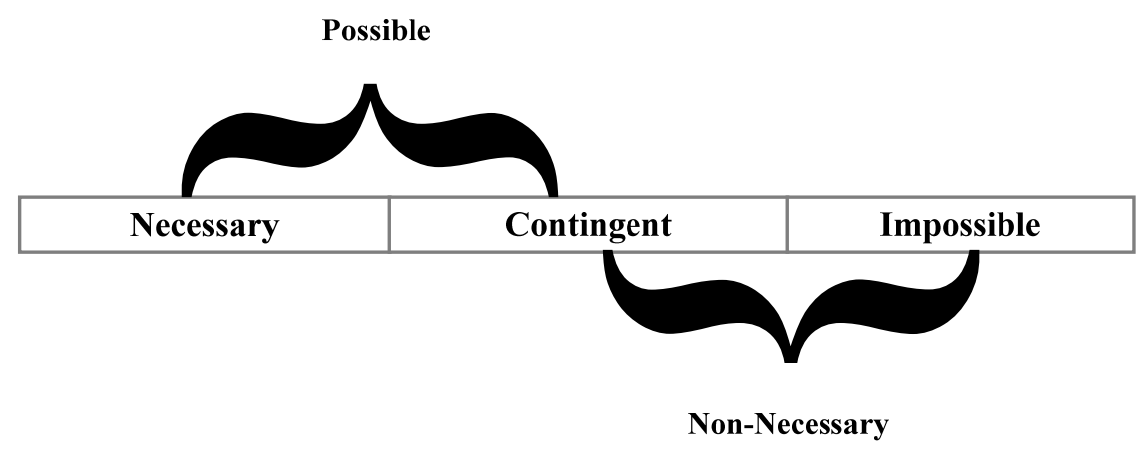

Figure 7: Deontic Logic Framework

The basic operators are:

It is possible that $\mathrm{a}(\diamond \mathrm{a})=\mathrm{df} \sim \square \sim \mathrm{a}$

It is impossible that $\mathrm{a}=\mathrm{df} \square \sim \mathrm{a}$

It is not necessary that $\mathrm{a}=\mathrm{df} \sim \square \mathrm{a}$

It is contingent that $\mathrm{a}=\mathrm{df} \sim \square \mathrm{a} \& \sim \square \sim \mathrm{a}$

When developing RDF we apply these rules supported by Activity Theory Notations. This will help it to be more machine and human understandable and interpretable. Let us take the case of writing an RDF for collective learning mode where the Normative constraint will be to restrict a direct connectivity of Pace setting in students mode. 


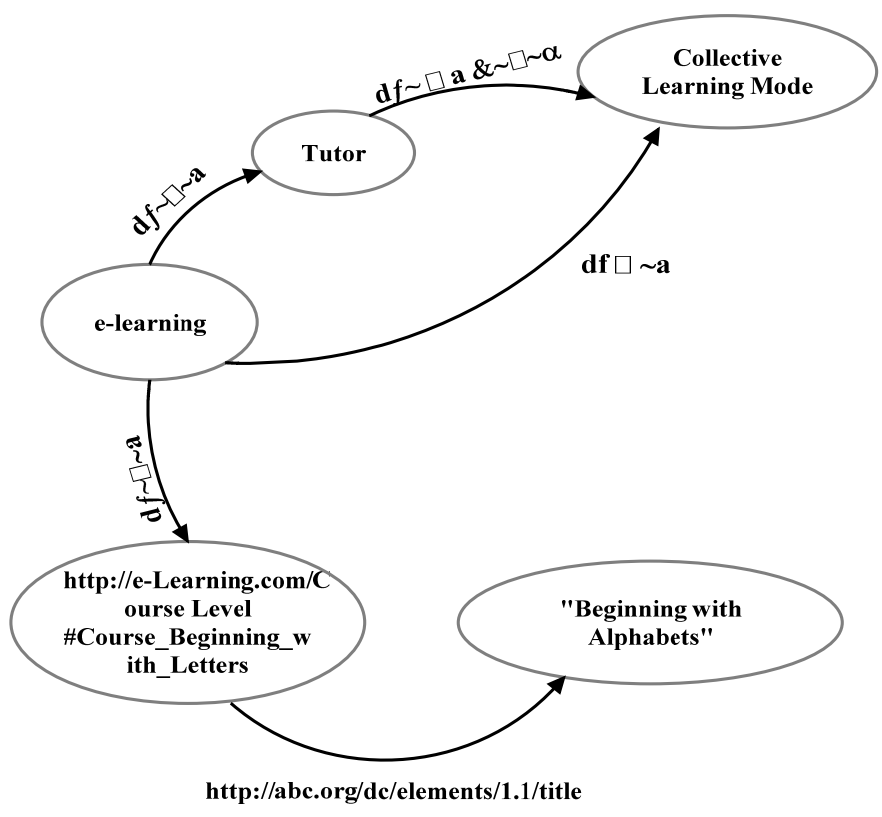

Figure 8: RDF Supported by Deontic Constraints

\section{Conclusion}

Fig. 8 represents Deontic constraints applied to the condition that "No student from collective Learning Mode can have a choice of selecting the Learning Pace". The use of Norm-AT framework provides a more refined machine and human understandable format. When linked with SPARQL it creates an excellent query support and knowledge base creation.

The paper concludes by suggesting a framework for E-Learning using Web 3.0. The main component that differentiates it from conventional e-Learning is the use of Normative Multi Agent System (Nor-MAS) and Activity Theory (AT). The NormATeL framework is applied for RDF generation and the constraint are symbolically verified using Deontic Logic. The future extension of the work includes generation of NormATeL language on principles of Deontics. 


\section{References}

Keegan, D.(1996), “Foundations of Distance Education”, 3rd edn, London: Routledge Press.

Bricken, W. (1990). Learning in virtual reality. Seattle, WA: Human Interface Technology Laboratory Technical Report HITL-M-90-5.

Karlsey,G. \& Shneiderman, B. (1998). Engagement theory: A framework for technology-based teaching and learning. Educational Technology, 38(5), 20-23.

Hayes, Gary.(2006) "Virtual Worlds, Web 3.0 and Portable Profiles." Personalize Media .

Vygotsky. L (1978), “Mind and Society”, Cambridge MA, Harvard University Press.

Engeström, Yrjö.(2001) "Expansive learning at work: Toward an activity theoretical reconceptualization." Journal of education and work 14.1: 133-156.

Mwanza, Daisy, and Yrjö Engeström (2005), "Managing content in E-learning environments." British Journal of Educational Technology 36.3, pp. 453-463.

Savarimuthu, Bastin Tony Roy, and Stephen Cranefield (2011) "Norm creation, spreading and emergence: A survey of simulation models of norms in multi-agent systems." Multiagent and Grid Systems 7.1: 21-54.

Chrisholm, Roderick.M(1963), “Contrary to Duty Impeartives and Deontic Logic”, Analysis,33-36

Brewka, Grchard (1989), “Non-Monotonic Logics: A Brief Overview”, AI Communications: The European Journal of Artificial Intelligence, 88-97.

Brown Mark A (1996), “Deontic Logic, Agency, and Normative Systems”, New York, Springer Verlag.

Guido Boella, Gabriella, Pigozzi and Leenderf, Toore, (2009) "NormativeFramework System Change", Proceedings of 8th International Conference on Autonomous Agents and Multi Agent System".

Jan Aasman, “Activity Recognition using a Web 3.0 Database", IEEE Computer Society, pp. 90-93.

Mathew J.Hoffman (2000)," Exploring Norm Emergence and Evolution: An Investigation with Agent Based Models", Annual Meeting of the Political Science Association, Washington DC, Poster Session.

Namrata Dhanda, Manuj Darbari, Neelu J Ahuja (2012) “Development of Multi Agent Activity Theory (MATeL) Framework Focussing on Indian Scenario", International Review on Computers and Software, Vol 7, No.4, pp. 1624-1628.

Xion Hui-Xang, Su Ying,(2010) "Study of Optimization of Personalised e-Learning system based on Web 3.0M", 2nd IEEE International Conferenceon Future Computer Communication, Vol 2, May. 
